contains about eight hundred separate titles. It is needless to emphasize the importance of such a survey for those working in this field.

Let us only mention a few of the main theories considered by the author. The theory of diophantine approximations has been taken in its widest sense, so that one also obtains information about neighboring theorems and applications. The book begins with a short survey of the field to obtain a classification of the main problems. One then finds a discussion of Minkowski's analysis, his Geometry of Numbers and applications to homogeneous and non-homogeneous linear forms. At this point one should also mention the account of Blichfeldt's methods. The properties of continued fractions are then discussed together with the neighboring theories, namely, of irrationality and transcendency and their measures. The approximation theorem of Kronecker is discussed at length. The distribution of real numbers $(\bmod 1)$ covers two chapters and one finds accounts of the investigations of Weyl, Vinogradoff, van der Corput, and others. The final chapter is devoted to the theory of diophantine inequalities.

\title{
Oystein Ore
}

Neuere Fortschritte in den exacten Wissenschaften. Fünf Wiener Vorträge. Ser. 3. Vitamine und ihre Bedeutung. By E. Späth. Die physikalischen Entdeckungen der letzten Jahre. By $\mathrm{H}$. Thirring. Extreme Versuchsbedingungen als Quelle des Fortschrittes. By H. Mark. Prinzipielle Fragen in der modernen Physik. By W. Heisenberg. Einige neuere Fortschritte in der exacten Behandlung sozialwissenschaftlicher Probleme. By K. Menger. Leipzig and Vienna, Franz Deuticke, 1936. 132 pp.

Five scholarly lectures by experts in physiology, physics, and social science are here presented. The first, on vitamins, is good but not novel. Professor Thirring's exposition of the discovery of the elementary particles of physics is systematic and up to his usual high standard. The third lecture is especially timely for mathematicians and theoretical scientists since it gives an account of the precision of the experimental determination of the major empirical constants which enter into physical theories. Perhaps the most unique and interesting of the lectures is by Heisenberg. $\mathrm{He}$ argues against a future reduction of the statistical aspects of quantum theory to causal laws. The final essay offers suggestive and original evidences of the application of mathematics and mathematical logic to social science. These lectures maintain a high level of excellence and merit the attention of serious students.

F. S. C. NORTHROP 